\title{
Failure mode in shear of steel fiber reinforced concrete beams
}

\author{
Julita Krassowska ${ }^{1, *}$, Marta Kosior-Kazberuk $^{1}$ \\ ${ }^{1}$ Faculty of Civil and Environmental Engineering, Bialystok University of Technology, Bialystok. \\ Poland
}

\begin{abstract}
Experimental tests were carried out to assess the failure model of steel fiber reinforced concrete beams. Experimental research was focused on observing changes in the behavior of the tested elements depending on the amount of shear reinforcement and the fiber. Model two-span beams with a cross-section of $80 \times 180 \mathrm{~mm}$ and a length of $2000 \mathrm{~mm}$ were tested. The beams had varied stirrup spacing. The following amounts of steel fibres in concrete were used: $78.5 \mathrm{~kg} / \mathrm{m}^{3}(1.0 \%)$ i $118 \mathrm{~kg} / \mathrm{m}^{3}(1.5 \%)$. Concrete beams without fibres were examined at the same time. The beams were loaded in a five-point bending test until they were destroyed. Shear or bending capacity of the element was observed. Fibre reinforced concrete beams were not destroyed rapidly, but they kept their shape consistent under load. Larger number of diagonal cracks with a smaller width were observed in fibre reinforced concrete beams. Failure of concrete beams without fibres was rapid, with a characteristic brittle cracking. Steel fibres revealed the ability to transfer significant shear stress after cracking in comparison to plain concrete.
\end{abstract}

\section{Introduction}

In recent years, the use of fibers as dispersed reinforcement in concrete is constantly growing. The increased interest the use of fibers exhibited by both concrete technologists and structure designers is related to the development of experimental studies confirming the beneficial effect that different types of fibers have on the properties of cement concrete $[1,2,3]$ Fibers used as dispersed reinforcement can be made of steel, glass, plastic, basalt, etc. The introduction of this type of reinforcement changes the properties of both fresh concrete mix and hardened concrete. A wide description of the research on the characteristics of fiber reinforced concrete can be found, among others, in the works of Lee and Jacobsena [4], Topçu and Canbaza [5], Fischera and Li [6].

In the case of structural concrete, steel fibers are more and more popular addition nowadays, because their presence changes the behavior of the concrete element under the load - from brittle to quasi-plastic [7, 8]. In comparison to ordinary concrete, concrete with steel fibers is characterized by higher bending tensile strength, and often also shear strength; paired with increased fatigue and impact resistance.

\footnotetext{
${ }^{*}$ Corresponding author: j.krassowska@pb.edu.pl
} 
Research on the application of concrete with steel fibers in structural elements have begun in the 1960s [9], and resulted in proposals for procedures and standards in testing methods and calculations of structures made of fiber reinforced concrete were created, including RILEM TC162-TDF [10] and fib Model Code 2010 [11]. In these standard recommendations the contribution of concrete in the shear stress transfer is included as a component of the loadbearing capacity of reinforced element, making the issue of estimating the load-bearing capacity of concrete fiber elements subjected to bending more important.-The design of fiber concrete structure is based mainly on the use of residual strength after cracking, provided by dispersed reinforcement [12]. The fibers can be used to improve the behavior of structure at the ultimate limit state, or to improve service conditions at the serviceability limit state. In the ultimate limit state, the addition of steel fibers can partially or completely replace the traditional reinforcement for tensile or shear $[13,14]$. However, material engineering issues related to the use of fiber reinforced concrete in structural elements are still insufficiently recognized, which makes it difficult to disseminate design methods that take the presence of dispersed reinforcement in concrete into account.

Shear failure can occur in reinforced concrete elements subjected to bending, mainly in support zones. This type of failure may cause a reduction of the load bearing capacity below the value of full bending capacity resulting from the longitudinal reinforcement used, and is particularly dangerous in elements without shear reinforcement [15]. The shear capacity is a complex issue that depends on many parameters. The main factors affecting shear capacity are: shear span-depth ratio, concrete strength characteristics, longitudinal reinforcement ratio, element dimensions and method of load $[12,14,15]$. The parameters recently listed in the literature include: type and grain diameters of aggregate, diameter of longitudinal reinforcement bars, spacing and inclination of cracks, conditions of the element support.

The aim of the work was to assess the impact of steel fibers on the shear resistance of a reinforced concrete beam. Two-span reinforced concrete beams with various shear reinforcement and different content of steel fibers in concrete were tested.

\section{Experimental programme}

\subsection{Materials}

Portland cement CEM I 42.5R was used to make concrete for structural elements. The cement content was $320 \mathrm{~kg} / \mathrm{m}^{3}$. A mixture of sand and gravel with grain size up to $4 \mathrm{~mm}$ was used as aggregate. The maximum size of aggregate was limited to reduce its influence on toughening mechanism and to provide the homogenous fiber distribution in concrete. Table 1 gives the mix proportions for reference concrete. The modified polycarboxylate and phosphonate based super-plasticizer ( $1 \%$ related to cement mass) was used to minimize fiber clumping and enhance fiber dispersion in concrete.

Table 1. Mix proportions of the reference concrete.

\begin{tabular}{|c|c|c|c|c|c|}
\hline$w / c$ & $\begin{array}{c}\text { Cement } \\
{\left[\mathrm{kg} / \mathrm{m}^{3}\right]}\end{array}$ & $\begin{array}{c}\text { Water } \\
{\left[\mathrm{kg} / \mathrm{m}^{3}\right]}\end{array}$ & $\begin{array}{c}\text { Aggregate } \\
0.125-2 \mathrm{~mm} \\
{\left[\mathrm{~kg} / \mathrm{m}^{3}\right]}\end{array}$ & $\begin{array}{c}\text { Aggregate } \\
2-4 \mathrm{~mm} \\
{\left[\mathrm{~kg} / \mathrm{m}^{3}\right]}\end{array}$ & $\begin{array}{c}\text { Superplasticizer } \\
{\left[\mathrm{kg} / \mathrm{m}^{3}\right]}\end{array}$ \\
\hline 0.5 & 320 & 160 & 1329 & 626 & 3.0 \\
\hline
\end{tabular}

The main reinforcement bars were made of RB500 steel. As a dispersed reinforcement, round hooked-end steel fibers with a length of $50 \mathrm{~mm}$ and a diameter of $1 \mathrm{~mm}$ were used. The tensile strength of steel of fibers was equal to $800 \mathrm{MPa}$. 


\subsection{Methods}

The strength properties of concretes with fibers and reference concretes were determined. The test of compressive strength was carried out in accordance with PN-EN 12390-3 [16] using cubic samples with $100 \mathrm{~mm}$ side size. The flexural strength was determined on specimens of size $100 \times 100 \times 400 \mathrm{~mm}$ according to PN-EN 12390-5 [17]. The elastic modulus was determined in accordance with PN-EN 12390-13 [18]. using cylindrical samples with a diameter of $150 \mathrm{~mm}$ and a depth of $300 \mathrm{~mm}$. Each series consisted of 3 samples.

In order to evaluate the failure mode of concrete beam with steel fibers, experimental studies were carried out, in which the emphasis was placed on analysing the behavior of tested elements depending on the amount of shear reinforcement and the amount of fibers. Fig. 1 shows the reinforcement schema for tested beams.

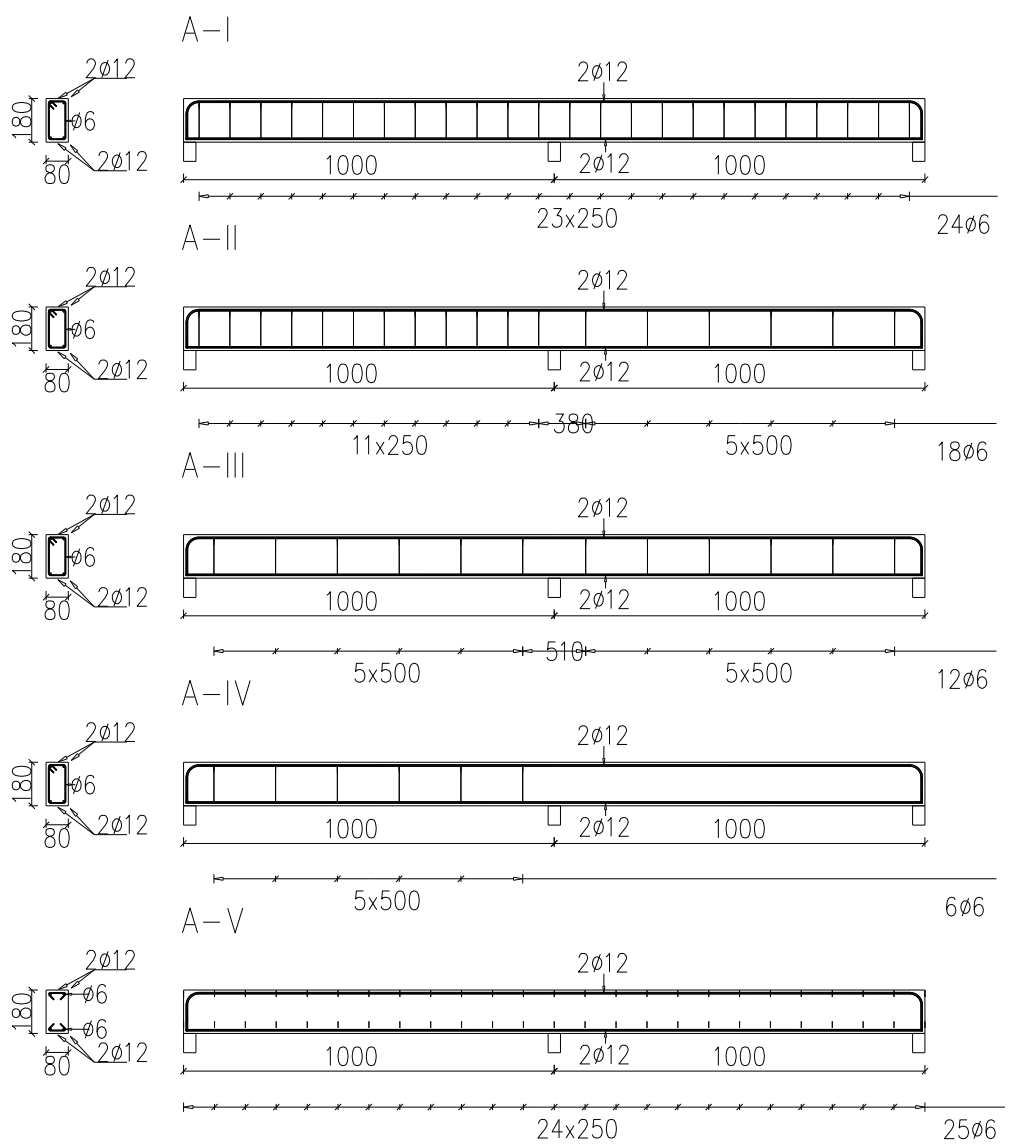

Fig. 1. Schema of reinforcement in beams tested.

Five series of two-span model beams with cross-sectional dimensions of $80 \times 180 \mathrm{~mm}$ and length of $2000 \mathrm{~mm}$ were made, each containing 5 elements with various dosage of steel fiber additions and with different stirrup spacing. Steel fibers were introduced into concrete in an amount of $78.5 \mathrm{~kg} / \mathrm{m}^{3}$, i.e. $1.0 \%$ by volume (WS1.0) and $118 \mathrm{~kg} / \mathrm{m}^{3}$, i.e. $1.5 \%$ by volume (WS1.5). The amounts of fibers were selected based on test results of post-cracking behavior of fine grained concrete, described in [20]. Comparably, reinforced concrete beams made of concrete without fiber (W0) were also tested. The amount of main longitudinal reinforcement and shear reinforcement were calculated in accordance with PN-EN 1992-1-1 [19], assuming 
a load in the form of concentrated force in the middle of each span. In each test series, the top and bottom reinforcements were identical and consisted of two $\phi 12 \mathrm{~mm}$ bars. The stirrups with diameter of $\phi 6 \mathrm{~mm}$ were used. The A-I series was made with stirrups spacing designed in accordance with the standard [19], then for each series the stirrups spacing was reduced. No stirrups were used in the A-V series. The shear span-depth ratio $a_{v} / d$ was equal to 2.7.

The beams were loaded in a five-point system. During the tests, the shear capacity and/or bending capacity of the beam were determined. The peak load and support reactions were also measured.

\section{Analysis of the test results of concrete properties}

Table 2 presents the results of strength properties tests: compressive strength $f_{c m}$, flexural strength $f_{c t m}$ and modulus of elasticity $E_{s}$ in dependence on the fiber content in concrete $\left(V_{f}\right)$ and changes in parameter mean values in relation to the reference concrete.

Table 2. Strength properties of concretes (average values and range of accuracy).

\begin{tabular}{|c|c|c|c|c|c|c|c|}
\hline Series & $\begin{array}{c}V_{f} \\
{[\%]}\end{array}$ & $\begin{array}{c}f_{c m} \\
{[\mathrm{MPa}]}\end{array}$ & $\begin{array}{c}\Delta f_{c m} \\
{[\%]}\end{array}$ & $\begin{array}{c}f_{c t m} \\
{[\mathrm{MPa}]}\end{array}$ & $\begin{array}{c}\Delta f_{c t m} \\
{[\%]}\end{array}$ & $\begin{array}{c}E_{s} \\
{[\mathrm{GPa}]}\end{array}$ & $\begin{array}{c}\Delta E_{s} \\
{[\%]}\end{array}$ \\
\hline W0 & - & $38.95( \pm 1.64)$ & - & $3.56( \pm 0.33)$ & - & $33.10( \pm 2.25)$ & - \\
\hline WS1.0 & 1.0 & $41.23( \pm 1.64)$ & 5.86 & $4.45( \pm 0.12)$ & 25.05 & $33.40( \pm 3.72)$ & 0.91 \\
\hline WS1.5 & 1.5 & $39.87( \pm 1.21)$ & 2.37 & $4.92( \pm 0.3)$ & 38.37 & $34.50( \pm 3.64)$ & 4.23 \\
\hline
\end{tabular}

The addition of steel fibers did not significantly affect the compressive strength $f_{c m}$ and the modulus of elasticity $E_{s}$. The increase in flexural strength $\Delta f_{c t m}$ for concretes with fibers in the amount of $1.0 \%$ and $1.5 \%$ was respectively $25 \%$ and $38 \%$.

\section{Analysis of two-span beams test results}

\subsection{Failure mode and cracking}

Table 3 shows the values of destructive load $P_{c r}$ and their increase in comparison to the values of destructive loads for the reference beams (without fibers). In the case of concrete beams with steel fibers, the increase in peak load ranged from $36.5 \%$ to $100 \%$.

The maximum load increase was observed for A-IV-WS1.5 series beams. Comparing the value of the destructive load in the A-I-W0 series with a typical longitudinal and shear reinforcement in accordance with the guidelines [19] with the force value in series A-IIIWS1.5, it can be concluded that reducing the number of stirrups by half while using concrete with the addition of steel fibers in $1.5 \%$ is enough to achieve required value of destructive force $P_{c r}$.

Table 3. Destructive load $P_{c r}$ and their increase $\Delta P_{c r}$ in particular series with steel fibers.

\begin{tabular}{|c|c|c|c|c|c|c|c|c|}
\hline \multirow{2}{*}{ Series } & \multicolumn{2}{|c|}{$\begin{array}{c}P_{c r} \\
{[\mathrm{kN}]}\end{array}$} & \multicolumn{2}{c|}{$\begin{array}{c}P_{c r} \\
{[\mathrm{kN}]}\end{array}$} & $\begin{array}{c}\Delta P_{c r} \\
{[\%]}\end{array}$ & \multicolumn{2}{c|}{$\begin{array}{c}P_{c r} \\
{[\mathrm{kN}]}\end{array}$} & $\begin{array}{c}\Delta P_{c r} \\
{[\%]}\end{array}$ \\
\hline A-I & A-I-W0 & 80.6 & A-I-WS1.0 & 110.0 & 36 & A-I-WS1.5 & 114.71 & 42 \\
\hline A-II & A-II-W0 & 57.8 & A-II- WS1.0 & 93.4 & 62 & A-II-WS1.5 & 109.7 & 90 \\
\hline A-III & A-III-W0 & 60.7 & A-III- WS1.0 & 64.1 & 6 & A-III-WS1.5 & 102.7 & 69 \\
\hline A-IV & A-IV-W0 & 29.9 & A-IV-WS1.0 & 47.6 & 59 & A-IV-WS1.5 & 60.0 & 101 \\
\hline A-V & A-V-W0 & 33.1 & A-V-WS1.0 & 47.0 & 42 & A-V-WS1.5 & 52.8 & 60 \\
\hline
\end{tabular}


The A-I series beams, in which the shear reinforcement provided the transfer of transverse forces, were destroyed in the compression zone by concrete crushing with wide cracks perpendicular to the element axis, caused by bending. The first crack appeared in crosssection with maximum value of tensile stress due to the bending moment. The structural element carried the loads as long as the adhesion of concrete and steel was not exhausted the elements reached the phase of successive cracks formation, in which the number of cracks increased. Cracks developed up to the neutral axis of beam and the longitudinal steel bars were responsible for stress transfer. At the limit state, the reinforcement in the cracked sections reached the yield point and the element was destroyed. The stirrups in the support zones ensured the transfer of shear stresses, and prevented the beams from destruction due to shear.

In the other series (A-II - A-V), in the majority of cases the failure due to shear occurred in the span, where the spacing of stirrups was reduced. Figs 2-4 present the model of failure of selected beams. There were diagonal cracks due to shear in the support zone. The morphology of these cracks formation is varied. At first, the perpendicular cracks appeared as a result of exceeding the tensile strength of concrete. Perpendicular cracks appeared much later in the case of elements made of concrete with steel fibers, due to their greater tensile strength. Rapid loss of the bearing capacity occurred when the shear cracks were accompanied by cracks associated with the loss of bond between steel and concrete. In some of the tested elements, a phenomenon of reinforcement slip occurred, as evidenced by splitting cracks (series A-II-WS1.0; A-IV-W0; A-IV-WS1.0; A-IV-WS1.5; A-V-WS1.0; AV-WS1.5). The phenomenon was caused by the lack or reduced number of stirrups in a given zone. In most cases, the destruction of the elements is a typical shear compression failure or shear tension failure. The cause of failure is the destruction of concrete in the compressive zone at the tip of the diagonal crack, where kind of pin joint appeared, around which two parts of the beams, separated by a crack, rotated with a simultaneous tangential movement. In the case of a beam series in a slip of reinforcement occurred, the opening of the first inclined crack significantly increased, and a series of small diagonal cracks appeared at the level of the main reinforcement, which indicated the bond failure between the main reinforcement and concrete. What is typical for this kind of failure, is that when the stresses in the main reinforcement are lower than the yield stress of steel, the complete loss of loadbearing capacity of reinforced concrete element can occur without warning.

The beams of concrete with steel fibers showed quasi-plastic features. The cross-section still carried full load after the crack appeared. In the reinforced beams of concrete with steel fiber, after exceeding the limit stresses there was no case of element failure due to concrete crushing. The presence of fibers allowed the development of multiple diagonal cracks and widening of at least one of them prior to shear failure, which provided some warning about the imminence of failure. The elements were destroyed by the extreme crack opening caused by pulling out steel fibers from cement matrix. The rate of element destruction depended on the content and shape of the fibers in the concrete.

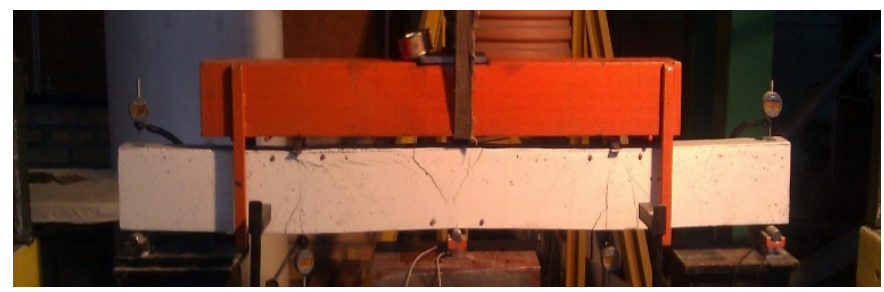

Fig. 2. Failure mode of A-I-W0 beam. 


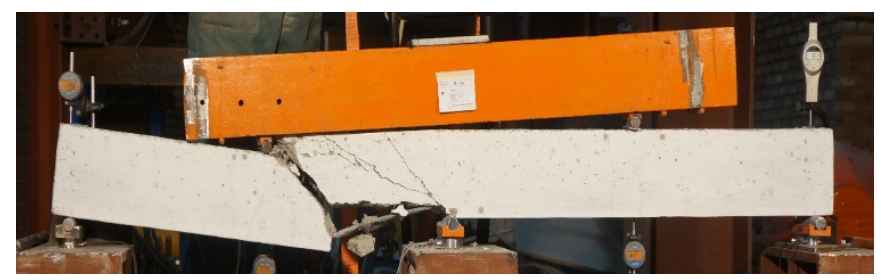

Fig. 3. Failure mode of A-IV-WS1.5 beam.

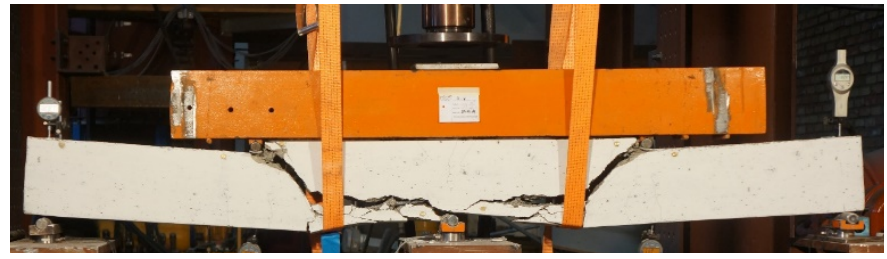

Fig. 4. Failure mode of A-V-WS1.0 beam.

\subsection{Shear stress analysis}

The dependencies presented in Figs 5 and 6 make the influence of steel fiber content on the shear stress $v_{u}=V_{u l t} / b d$ clearly visible. The values of stress were determined at three supports. The graphs show the dependence of shear stress on the content of steel fibers in concrete. The shear stress values were calculated on the basis of the shear force at failure $V_{u l t}$.

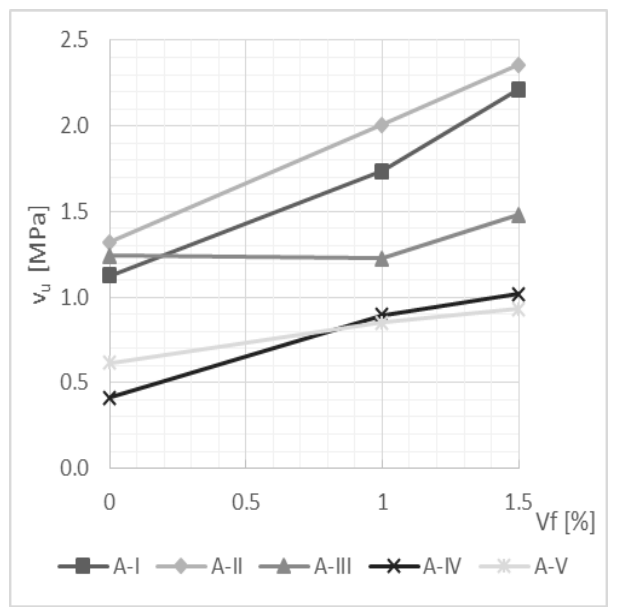

Fig. 5. Shear stress $v_{u}$ versus fibre content $V_{f}$ at the central support. 
a)

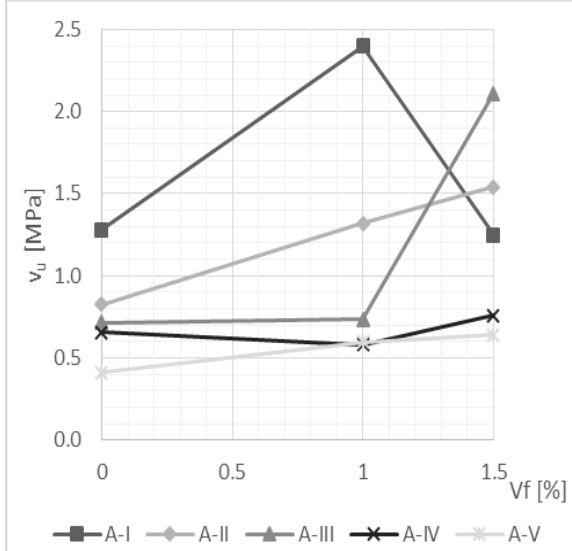

b)

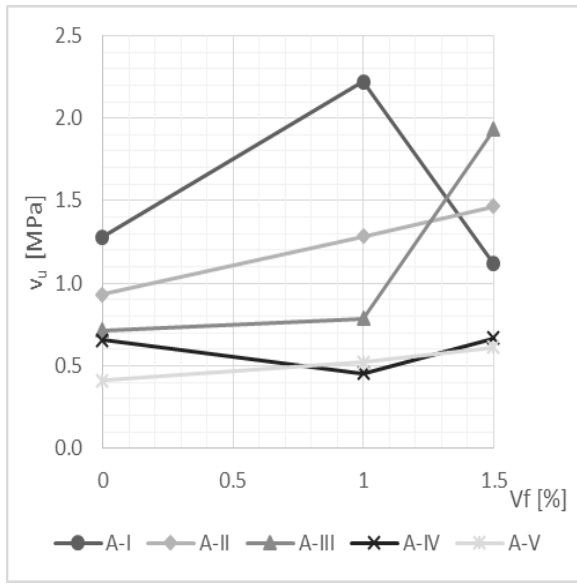

Fig. 6. Shear stress $v_{u}$ versus fiber content $V_{f}$ at the left support (a) and right support (b).

Analyzing the shear stresses at the central support, it can be concluded that in the case of a series of concrete beams with steel fiber, the higher the fiber content in the concrete, the higher the stresses at failure. The highest shear stress was recorded in the case of the A-II series, where in the right span the stirrup spacing was reduced by half in relation to that required by the standard [19]. The largest increase in shear stress due to the effect of dispersed steel reinforcement was obtained for the A-IV series.

The effect of dispersed steel reinforcement on both edge supports was similar. The highest stresses were obtained in beam series where stirrups and dispersed reinforcement were used. Compared to beams without dispersed reinforcement, the increase in shear stresses at failure was significant. In series A-III-WS1.5, the reactions during tests reached similar values on all supports due to the quasi-plastic behavior of fiber reinforced concrete. The failure process was running smoothly as long as the bond between steel fibers and concrete was transferring shear stress. The fiber bridging effect contributed to uniform redistribution of stresses in the cross-section weakened by the crack. In the series A-I-WS1.5, the stresses on the edge supports decreased significantly, which resulted from the failure mode due to bending. In this series, the reaction at the central support achieved the greatest value.

\section{Conclusions}

The following conclusions can be drawn from the results of the experimental investigation.

- The stiff, hooked-end steel fibres (incorporated in the volume fraction of 1.0 and $1.5 \%$ ) influenced concrete performance effectively. The flexural tensile strength and the ductility increased in line with increasing fibre volume as expected.

- Steel fibers directly influenced the shear capacity of concrete beams. Inclusion of fibers can transform brittle shear mechanism into ductile flexural mechanism. The obtained results confirm the potential possibility of using fibers to partially replace the stirrups. The combination of stirrups and steel fibers can improve both the ultimate and shear cracking strength. Analyzing the shear stresses on the central support of two-span beams, it can be concluded that in the case of steel fiber series, the higher the fiber content in the concrete, the higher the stresses at failure. The largest increase in shear stress at failure due to the effect of dispersed steel reinforcement was obtained in the A-IV series with a highly reduced number of stirrups. 
- Awareness of the dispersed reinforcement influence on the shear capacity of element subjected to bending can also be helpful in determining the minimum shear reinforcement needed to protect the element against a sudden brittle failure.

This research work was financially supported by National Centre for Research and Development, Poland; project number PBS3/A2/20/2015 (ID 245084).

\section{References}

1. T. Domański, A. Czkwianianc, Przegląd Budowlany 6, 32-36 (2006) (in Polish)

2. W. Głodkowska, J. Kobaka, Constr. Build. Mater. 44, 645-653 (2013)

3. A. Khaloo, E.M. Raisi, P. Hosseini, H. Tahsiri, Constr. Build. Mater. 51, 179-186 (2014)

4. S.F. Lee, S. Jacobsen, Mater. Struct. 44, 1451-1465 (2011)

5. I.B. Topçu, M. Canbaza, Constr. Build. Mater. 44, 1486-1491 (2007)

6. G. Fischer, V.C. Li, Eng. Fracture Mechanics 74, 258-272 (2007)

7. J. Michels, R. Christen, D. Waldmann, Eng. Fracture Mechanics 98, 326-349 (2013)

8. F.A. Farhat, D. Nicolaides, A. Kanellopoulos, B.L. Karihaloo, Eng. Fracture Mechanics 74, 151-167 (2007)

9. J. Romualdi, J. Mandel, ACI J. Proc. 61, 657-672 (1964)

10. RILEM TC 162 - TDF 36, 560 - 567 (2003)

11. A. Ajdukiewicz, J. Walraven, fib Model Code 2010. Pre - norma Konstrukcji Betonowych. Tom 1 (SPC, Kraków 2014)

12. M. Kamiński, C. Bywalski, M. Kaźmierowski, Materiały Budowlane 6, $76-77$ (2014)

13. Q. Chuxiang, I. Patnaikuni, Cem. Concr. Comp. 21, 73-81 (1999)

14. H.H. Dinh, G.J. Parra-Montesinos, J.K. Wight, ACI Structural J. 107, 597-606 (2010)

15. M. Słowik, Nośność na ścinanie zginanych elementów żelbetowych bez zbrojenia poprzecznego, (Wyd. Politechnika Lubelska, Lublin, 2016).

16. PN-EN 12390-3 (2011)

17. PN-EN 12390-5 (2011)

18. PN-EN 12390-13 (2014)

19. PN-EN 1992-1-1 (2008)

20. M. Kosior-Kazberuk, J. Krassowska, Budownictwo i Inżynieria Środowiska (Civil and Environmental Engineering) 6(2), 73-80 (2015) 